\title{
BREVE ENSAIO SOBRE MÍDIA E SUAVIZAÇÃO DE PRÁTICAS LINGÜÍSTICAS
}

\section{A BRIEF ESSAY ABOUT MEDIA AND SOFTENING PROCESSES OF LINGUISTIC PRACTICES}

\author{
Roberto Leiser Baronas*
}

RESUMO: Neste texto, com base nas idéias de Norbert Elias, Michel Foucault, Jean-Jacques Courtine e Michel Pêcheux, procuramos refletir sobre o papel dos mais diversos suportes midiáticos no desencadeamento de um verdadeiro processo suavizatório dos costumes lingüísticos a partir do mito da língua portuguesa única. Ilustram nossa reflexão alguns acontecimentos discursivos sobre saberes metalingüísticos, dizeres avaliativos sobre a língua veiculados pela mídia brasileira entre os anos 2000 e 2004. A nossa análise evidencia que, atualmente, todos os nossos sentimentos e práticas são calculados, espetacularizados e positivados por uma espécie de humanismo político midiático de boas intenções.

PALAVRAS-CHAVE: discurso, mídia, civilização de costumes.

\begin{abstract}
In this text, based on the ideas of Norbert Elias, Michel Foucault, Jean-Jacques Courtine e Michel Pêcheux, we attempt at reflecting on the role of the most diverse mediatic supports in the triggering of a softening process of linguistics customs. Some discursive events about linguistic knowledge, specifically evaluative speech about the language shown by the media between the years of 2000 and 2004, illustrate our reflection. The analysis shows that currently all our feelings and practices are evaluated, spectacularized and made positive by a sort of mediatic political humanism of good intentions.
\end{abstract}

KEY WORDS: discourse, media, civilization of customs.

\footnotetext{
* Roberto Leiser Baronas é Doutor em Lingüística e Língua Portuguesa pela Universidade Estadual Paulista, Campus de Araraquara e Université de Paris XII, professor de Lingüística no Departamento de Letras e no Programa de Pós-Graduação em Lingüística da Universidade Federal de São Carlos - UFSCAR e professor colaborador no Mestrado em Estudos da Linguagem da Universidade Federal de Mato Grosso - UFMT.
} 



\section{BREVE ENSAIO SOBRE MÍDIA E SUAVIZAÇÃO DE PRÁTICAS LINGÜÍSTICAS}

Tudo à venda cdtvcinema o gênio da raça a mortalidade infantil a má distribuição de renda a comunicação de massa a injustiça do sistema o risco Brasil nenhum poema.

(Augusto de Campos)

\section{0) Primeiras palavras}

Nos últimos anos a língua portuguesa tem aparecido com certa freqüência em diferentes mídias. Há desde programas televisivos em que alunos de diferentes estados competem entre si, realizando provas de "soletração" até sites especializados que se propõem a tirar dúvidas de português. Embora tais suportes falem de língua a partir de diferentes enfoques "mais seriamente" ou "menos seriamente", como é o caso dos programas de entretenimento, é possível perceber que todos olham para a língua com base num único mirante, ou seja, como se ela fosse algo homogêneo e que passa por um processo de degradação, de corrupção. Procuramos refletir neste texto sobre o papel dos mais diversos suportes midiáticos brasileiros no desencadeamento de um verdadeiro processo suavizatório dos costumes lingüísticos. Processo esse que se alicerça no mito da língua portuguesa única. Nossas discussões apóiam-se fortemente nas reflexões de Norbert Elias, Michel 
Foucault, Jean-Jacques Courtine e Michel Pêcheux. Ilustram nossa reflexão alguns acontecimentos discursivos sobre saberes metalingüísticos, dizeres avaliativos sobre a língua portuguesa veiculados pela mídia brasileira entre os anos 2000 e 2004. Tomar discursivamente tais acontecimentos significa compreendê-los na sua materialidade histórico-lingüística. Essa materialidade, embora se realize na língua, é distinta tanto da maneira como os lingüistas a concebem quanto da maneira quanto os historiadores a definem. Trata-se de pensar como um conjunto de condições histórico-lingüísticas, enquanto princípios de controle, de delimitação e de rarefação de discursos possibilitam que o sujeito falante constitua-se "em sujeito do seu discurso e ao qual ele se assujeita em contrapartida" (COURTINE, 1999, p. 16).

A nossa análise evidencia que, atualmente, todos os nossos sentimentos e práticas são calculados, espetacularizados e positivados por uma espécie de humanismo político midiático de boas intenções. Na verdade, trata-se de um movimento midiático ocidental que se constitui numa espécie de cruzada iluminista apta a esclarecer sobre o bom uso da língua, pedofilia, machismo, drogas, homossexualismo, violência doméstica, idosos, ecologia, armas, preconceito racial, produzindo e comercializando um imaginário de cidadania. Nesse momento, nada, nem ninguém escapa desse fundamentalismo mercadológico de ocidentais bons costumes. Tudo deve passar pelo crivo dessa "gestão das diferenças", da reforma dos costumes, cujo objetivo é discipliná-los, ordená-los, esquadrinhá-los, transformandoos em eficazes instrumentos para a domesticação do indivíduo necessária à existência e à auto-regeneração da sociedade capitalista.

Nessa empresa, que se auto-representa como uma espécie de cruzada religiosa, não há mais limite entre o público e o privado, entre o real e o ficcional, entre a fabulação e a dramatização. Instaura-se uma nova maneira de o capital se relacionar com as subjetividades. Décadas atrás, o capital se apropriava da força produtiva dos indivíduos; agora, além dela, ele se apropria dos seus corpos.

Contudo, hoje, por meio da mídia, o capital capilariza-se, transforma-se em "mil poderezinhos" vigiando e controlando o corpo dos indivíduos, mas também mobilizando-os, pondo-os para trabalhar. Ele os explora, amplia, constitui-os por meio da criação de determinadas necessidades, o que produz um sujeito disciplinado e auto-disciplinarizante, inscrito em determinados padrões, definidos pelo "olhar-leitor-mercado" como válidos. A fórmula miraculosa do Panóptico de 
Bentham mudou-se dos projetos arquitetônicos das prisões para as cabeças dos indivíduos.

Os mais diversos suportes midiáticos brasileiros anunciaram no final de outubro de 2004 que o escritor Mauricio de Souza, criador da Turma da Mônica e de outras personagens em quadrinhos, daria um banho na personagem Cascão, conhecida do grande público brasileiro como avessa a esse tipo de prática. A justificativa para o banho do cascão era a de que essa personagem, por não tomar banho, seria um exemplo pernicioso para as crianças brasileiras.

Além do "necessário" banho da personagem Cascão, um outro acontecimento discursivo, ocorrido recentemente na França, ilustra bem o que estamos asseverando. A Editora Gallimard viu-se obrigada a colocar uma nota de advertência na capa do livro chamado Rose Bonbon, esclarecendo que se tratava de uma obra de ficção, em razão de os meios de comunicação franceses comercializarem a idéia de que esse livro, por narrar a história de uma suposta personagem pedófila, estaria fazendo uma espécie de apologia à pedofilia.

Rose bonbon est une œuvre de fiction. Aucun rapprochement ne peut être fait entre le monologue d'un pédophile imaginaire et une apologie de la pédophilie.

C'est au lecteur de se faire une opinion sur ce livre, d'en conseiller ou d'en deconseiller la lecture, de l'aimer, de le détester, en toute liberté.

GALLIMABD

Os exemplos aqui mostrados não passariam de mais uma de tantas outras efemeridades desta contemporaneidade excludente em que "tudo o que é sólido desmancha no ar", como diria Marx, não fosse a preocupante legitimação gradativa de um humanismo moralizante suavizatório, que assevera a necessidade cotidiana de os indivíduos se corrigirem, conformarem-se a determinados padrões de comportamento tidos como politicamente corretos. Os exemplos arrolados evidenciam também que nesta era da biopolítica nem as discursividades literárias, as que são o "domingo do pensamento", escapam dos princípios de controle e rarefação dos discursos. 


\section{0 poder como tecnologia: olhar-leitor}

Norbert Elias, na década de 1930, do mirante analítico da sociologia histórica talvez tenha sido um dos primeiros estudiosos a se debruçar sobre a civilização dos costumes. Em seu estudo sobre a sociedade da corte, o autor nos mostra como os impulsos e os instintos das pessoas vão sendo reprimidos em favor de um modelo que entende a etiqueta como forma de distinção e reconhecimento de civilização das camadas mais nobres. Elias analisa então o papel da literatura e dos tratados de bons costumes na disseminação e cristalização dos valores burgueses nas sociedades ocidentais. Esses costumes tidos como civilizados é que serviram de modelo para a constituição não só da conduta dos indivíduos ocidentais, bem como dos seus sentimentos. Michel Foucault, diferentemente de Norbert Elias, pensará a civilização dos costumes como práticas de subjetivação dos indivíduos, ou seja, o modo mesmo pelo qual o ser humano passa a ser sujeito. Dito de outro modo, Michel foucault principalmente na sua fase genealógica, irá refletir como os indivíduos são instados a necessitarem de determinadas subjetivações.

A extensa obra de Michel Foucault pode ser lida a partir de três grandes arquiteturas: o poder, o sujeito e a verdade. Há em Foucault não apenas um esboço, mas toda uma teoria sobre essas três grandes arquiteturas. Neste texto, elejo o conceito foucaultiano de poder como mirante de análise e, seguindo grosseiramente a trilha deixada por esse filósofo francês para tentar "colocar em evidência as relações de poder, de ver onde elas se escrevem, de descobrir seus pontos de aplicação e os métodos que elas utilizam" (2003, p. 229), trabalharei com a categoria de poder na sua acepção técnica-estratégica-positiva ${ }^{1}$, refletindo um pouco mais acuradamente sobre as condições que possibilitaram a irrupção, a germinação, o desenvolvimento e a existência de discursos que dizem avaliativamente o português brasileiro não-canônico na última década. É notório que, de aproximadamente uma década para cá, essa espécie de assédio lingüístico tem recalcitrado bastante. Para comprovar o que estamos dizendo, basta folhear uma das revistas

\footnotetext{
1 Em Les mailles du pouvoir (1981, p. 34), Foucault, discordando dos psicanalistas, dos psicólogos e dos sociólogos para quem o poder teria simplesmente uma concepção jurídiconegativa, diz-nos que o poder, "além de classificar os indivíduos em categorias, designá-los pela sua individualidade própria, liga-os a sua identidade, impõe-lhes uma lei de liberdade que é necessário reconhecer e que os outros devem reconhecer. Em suma, é uma forma de poder que transforma os indivíduos em sujeitos".
} 
ou dos jornais de grande circulação nacional e verificar o grande número de textos a respeito da forma "correta" de utilizar a língua portuguesa. São "sugestões" do tipo "não erre mais", aprenda a "melhorar a comunicação" no trabalho, na vida social, etc.

O sentido não se constitui meramente como tradução de dados da realidade, mas principalmente "no poder do qual queremos nos apoderar". Com efeito, "por mais que aparentemente o discurso seja bem pouca coisa", estamos o tempo todo lutando pelo direito de produzir sentidos. O discurso "serve para comunicar e para não-comunicar" (PÊCHEUX, 1990, p. 21), pois é a um só tempo um objeto simbólico e político, simbólico no sentido de que ele não é uma etiqueta que representa um determinado objeto cuja ordenação, categorização, interpretação preexiste à significação e político no sentido de que é uma luta pelo poder, "afrontamento, relação de força, situação estratégica. Não é um lugar, que se ocupa, nem um objeto, que se possui. Ele se exerce, se efetua, que funciona" (MACHADO, 1999, p. 14). Um poder que, nos termos de Courtine (2002, p. 2),

controla os homens sob um olhar visível e ao mesmo tempo invisível, contínuo e meticuloso, que espia e detalha cada um deles. O dispositivo que permite essa vigilância surda e minuciosa converteu, desse modo, a sociedade inteira em uma superfície de leitura: o corpo social tornou-se um texto e o corpo de cada sujeito, um sinal em que uma leitura atenta espreita os desvios mais sutis: a escapulida de uma palavra, a sombra de uma dúvida, a passagem de um problema, a bruma de uma emoção.

Nada, ninguém escapa desse olhar-leitor, que esquadrinha, ordena, positiva a correção. Uma semântica do poder que aperfeiçoa deslocando, apagando o sujeito. Essa "vasta empresa de reeducação", contudo, não é feita à base do "é proibido, você não deve", mas por um outro modalizador: "você pode, você consegue". Para isso, basta que o indivíduo tenha boa vontade, que se liberte dos seus costumes retrógrados, que substitua a doença do antigo pela sanidade do novo, cura que começa pela língua, fazendo desaparecer "os usos antigos e obscuros, apagando neles os pontos de impalpabilidade, as zonas de indeterminação - ambigüidade, equívoco polissemia" (COURTINE, 2002, p. 3). Cria-se um novo código de conduta moral: é preciso purgar, purificar a língua desse lixo atômico-lingüístico da pluralidade. Irrompem os "ecolingüistas". 


\section{Das condições de possibilidade às condições de existência}

Diante das práticas desses "ecolingüistas", uma pergunta se torna inevitável: quais são as razões para essa verdadeira enxurrada dos discursos que dizem avaliativamente a "nossa" língua? Ou, o que leva(ou) tantas pessoas - quer sejam especialistas ou não - a enunciarem sobre esse assunto? Como sujeitos das mais diferentes classes sociais, que vêem o mundo de diferentes mirantes, em um mesmo momento histórico, foram levados a produzir um conjunto de enunciados que instauram um único objeto de saber, inscrevendo-se numa única "formação discursiva" (FOUCAULT, 1995, p. 43)? Tais enunciados advogam desde a "nostradâmica profecia" do fim do português (Revista Veja, 05/04 de 2000) até a legitimação de um "Movimento Nacional em Defesa da Língua Portuguesa”.

Uma das possíveis respostas, talvez a mais corrente, alicerçada num explícito preconceito lingüístico, seria a de que o brasileiro fala e escreve mal o português. Desse modo, foi necessário que os defensores do idioma pátrio desencadeassem uma verdadeira cruzada ${ }^{2}$ contra as deficiências comunicativas dos brasileiros, uma versão modernizada e midiatizada nos mais diferentes suportes do Diretório Pombalino de $1759^{3}$.

Marcos Bagno, em sua "Dramática da Língua Portuguesa" (2000, p. 1089), oferece-nos uma boa hipótese para explicar essa "neogramatiquice contemporânea":

pode ser que o atual movimento neogramatiqueiro se prenda a uma necessidade de buscar uma linguagem pura, um código sagrado ou secreto que permita uma comunicação mais perfeita. Descrente dos métodos tradicionais de ensino

2 Para Le Goff \& Schimitt, no "Dicionário temático do Ocidente Medieval”, o emprego da palavra cruzada carrega consigo a marca de Deus, ou seja, "se Deus existe, não compete ao homem se envolver em suas ações. Ele seria grande o suficiente para fazer o que quer. De modo que a definição de delitos como "cruzadas" introduz imediatamente a intolerância, uma hostilidade de tipo religioso, que se vê sobretudo nos monoteísmos". (2002, p. 48).

${ }^{3}$ Segundo Pombal, "para desterrar este perniciosíssimo abuso, será um dos principais cuidados do Diretório estabelecer nas suas respectivas povoações o uso da língua portuguesa, não consentindo por modo algum que os Meninos e as Meninas, que pertencem às escolas, e todos aqueles índios que forem capazes de instrução nesta matéria, usem da língua Geral, mas unicamente a Língua Portuguesa, na forma que S. M. tem recomendado em repetidas Ordens, que até agora não se observaram, com total ruína temporal e espiritual do Estado." (apud CUNHA, 1975, p. 56, os grifos são nossos). 
(tal como há descrédito das grandes religiões tradicionais), os novos peregrinos recorrem aos mestres iluminados do idioma, que têm as fórmulas de acesso ao nirvana da língua padrão. De fato, os comandos paragramaticais têm função similar aos dos livros e outras manifestações multimidiáticas de auto-ajuda: mostrar um caminho diferente, melhor, que permita ao indivíduo subtrair-se ao caos da modernidade estressante.

Em outras palavras, vivendo em uma sociedade "endemicamente depressiva", a língua canônica seria para o sujeito uma espécie de "antidepressivo de última geração" (ARANTES, 2002, p. 11), pois com ela o sujeito poderia, além de se expressar com maior clareza, ter condições de diminuir seus "pecados" junto ao Criador do Universo. Parece-me que o homem tenta se redimir da "blasfema da Torre de Babel", reestabelecendo a Língua Perfeita com a qual Adão se comunicava com Deus (ECO, 2001, p. 55). Uma busca incessante pela vitória da transparência frente à opacidade da linguagem. Nos termos de Courtine (2002, p. 5), "a transparência da língua redobra o plano geométrico das cidades utópicas, o nivelamento de uma paisagem cujas montanhas foram às vezes apagadas, a harmonia reina entre os sexos e as classes", entre a língua e a sua diversidade, acrescentaria. Dessa forma, esse modelo de língua funcionaria como um "agalma, tesouro, objet(a). A 'pureza' torna-se causa de um desejo, e o purista é o sujeito a quem ela faz signo na língua” (MILNER, 1987, p. 22).

Entretanto, pensamos que a língua como um precioso antidepressivo explica somente uma pequena parte da pergunta, pois não consegue explicitar as condições de possibilidade de irrupção dessas práticas dos/nos sujeitos. Acreditamos que outra resposta bem mais complexa poderia ser buscada em algumas das atuações da mídia na atual "sociedade do controle" "FOUCAULT, 1999). Estamos nos referindo ao papel desastroso desse aparelho ideológico na transformação dos mais diversos sistemas simbólicos em mercadoria.

\footnotetext{
4 Michel Foucault em $A$ verdade e as formas jurídicas, diz-nos que o mundo ocidental, a partir do final do século XVII, passou a viver numa espécie de sociedade do controle, tendo o "panoptismo como um de seus traços característicos. É uma forma de poder que se exerce sobre os indivíduos em forma de vigilância individual e contínua, em forma de controle, de punição, de recompensa e em forma de correção, isto é de formação e de transformação dos indivíduos em função de certas normas. Este tríplice aspecto do panoptismo - vigilância, controle e correção - parece ser uma dimensão fundamental e característica das relações de poder que existem em nossa sociedade" (1999, p. 103)
} 
Estamos asseverando que a proliferação de discursos que dizem avaliativamente o português não-canônico do Brasil está intimamente relacionada com a transformação da língua em mercadoria. Assim, a língua, que era o veículo pelo qual as mercadorias eram anunciadas e vendidas, transformase, no momento atual, em mercadoria também. Ou seja, industrializa-se a língua de maneira semelhante à industrialização de um automóvel, pratica-se uma espécie de taylorismo lingüístico, que, a partir de uma renaturalização do mito da identidade língua/gramática, vende não um produto, mas a possibilidade de o sujeito concretizar seus desejos. Exemplos do que estamos enunciando podem ser observados no folder que acompanhou, quando do seu lançamento, a Gramática Escolar da Língua Portuguesa, de Evanildo Bechara:

Preparando-se para conquistar seus ideais? Conheça um caminho seguro para vitória. Esta nova obra do Prof. Evanildo Bechara visa a preparar o leitor para utilizar com eficiência e correção, falando ou escrevendo, esse instrumento maravilhoso e fundamental de comunicação, a linguagem humana (Editora Lucerna, novembro de 2001).

Ou na reportagem da Revista Veja de 07 de novembro de 2001, "Falar e Escrever, Eis a Questão": "a verdade é que as pessoas finalmente perceberam que precisam dominar a norma culta do idioma. Principalmente na vida profissional. [...] quem não consegue articular pensamentos com clareza e correção tem um grande entrave à ascensão da carreira”. Ou, ainda, no artigo de Diogo Mainardi "Os Pronomes e a Rússia”, publicado também na Revista Veja em 22 de março de 2000: "por isso eu digo que, resolvendo as ambigüidades acerca dos pronomes e prenomes, fica mais fácil acertar o resto, diminuindo o desemprego, a violência, o déficit na balança de pagamentos. Acreditem em mim".

Os três exemplos arrolados são indícios da transformação do saber metalingüístico canônico em mercadoria, submetendo-a às leis do mercado. Com efeito, não uma mercadoria qualquer, mas um produto que daria conta de resolver problemas individuais e até coletivos. Ademais, é justamente essa extrema valorização da língua padrão como algo positivo que possibilita que os sujeitos se tornem cúmplices de sua própria submissão lingüística. A esse respeito nos diz Bourdieu (1998, p. 38): 
O reconhecimento da legitimidade da língua oficial não tem nada a ver com uma crença expressamente professorada, deliberada e revogável, nem com um ato intencional de aceitação de uma "norma". Através de um lento e prolongado processo de aquisição, tal reconhecimento se inscreve em estado prático nas disposições insensivelmente inculcadas pelas sanções do mercado lingüístico (...) às possibilidades de lucro material e simbólico que as leis de formação dos preços característicos de um determinado mercado garantem objetivamente aos detentores de um certo capital lingüístico.

Dito de outro modo, por intermédio de um complexo processo de criação de necessidades dos/nos sujeitos, a mídia, nos seus mais diversos suportes, intervém na sociedade disseminando normas de conduta, que seriam capazes de suprir essas necessidades dos/nos sujeitos.

A história secreta e silenciosa de um povo, se fosse escrita, nos revelaria maiores crueldades com os que sequer falam em certas circunstâncias, por serem considerados (até por si mesmos como fruto de uma ideologia da forma lingüística), incapazes de falar. E quando falam, o preço que pagam é alto em chacotas, perda de oportunidades de trabalho e de certos espaços sociais, reservados aos que dominam a "boa linguagem". (POSSENTI, 1993, p. 120 - 1).

Caso o sujeito não consiga suprir suas "deficiências lingüísticas", o problema estaria nele mesmo. Ou seja, ele é o único responsável pelo próprio "fracasso lingüístico". Assim, "a linguagem, à medida que comunica, produz mercadorias, [e se reproduz como mercadoria], mas além disso, cria subjetividades, põe em relação umas às outras, e ordena-as" (HARDT \& NEGRI, 2001, p. 52).

\section{3. (In)conclusões preliminares: olhar-leitor-mercado sobre a língua}

A língua canônica é oferecida aos sujeitos a partir das necessidades que estes "têm" de consumi-la. São necessidades das mais diferentes ordens: ascender na carreira; passar num concurso público; arrumar um bom emprego; melhorar a comunicação nas mais diversas situações de trabalho e da vida social, etc. O mais nefasto nessa positivação do saber metalingüístico canônico como mercadoria é a conseqüente criação de subjetividades. Com efeito, o que a mídia nos seus mais diversos suportes vende ao sujeito não é um produto, mas a possibilidade de um acesso na forma de fantasia. 
Desse modo, não uma há sublimação, mas uma repreensão pela falta de algo que o sujeito efetivamente não necessita. Os indivíduos são controlados na sociedade não somente por meio da consciência ou da ideologia, o que produziria uma espécie de dessubjetivação do sujeito, mas também no corpo e com o corpo, o que produz um sujeito disciplinarizado.

O corpo é o objeto das disciplinas; não apenas enquanto alvo das ações disciplinares, mas também enquanto sede capaz de pensar de uma maneira ordenada e representacional e, por aí, capaz de dar um sentido particular àquilo que pensa. A disciplinaridade passa a funcionar como uma matriz de fundo que, por si só, impõe ao corpo determinados códigos de permissão e de interdição e maneiras muito peculiares de pensar [e agir] (n)o mundo. (GREGOLIN, 2002, mímeo).

Para a sociedade capitalista, a biopolítica é o que mais importa, o biológico, o somático, o físico" (FOUCAULT, 2000, p. 210). Ou seja, a sociedade do controle desenvolve modernas tecnologias de poder cujo foco é a vida, "um poder destinado a produzir forças, a fazê-las crescer e a ordená-las mais do que barrá-las, dobrá-las ou detruí-las" (FOUCAULT, 1977, p. 128). Desde o seu nascimento, por meio de práticas sociais de controle e de vigilância, é impresso no indivíduo um código de conduta moral e penal que o torne uma pessoa perfeita: sadia, crente, dócil, íntegra, sensata, bem comportada, infatigável, que fale e escreva o "bom português". Trata-se de um biopoder, um poder cujo fundamento é o de disciplinar ao máximo a vida dos sujeitos. Ademais, os indivíduos são controlados e vigiados na sociedade não somente por meio da consciência ou da ideologia, o que resultaria numa espécie de sujeição do sujeito, mas também no corpo e com o corpo pelo biopoder, o que produz um sujeito disciplinarizado, inscrito em determinados padrões, definidos pelo "olhar-leitor-mercado" como válidos.

Nesse sentido, ousaríamos dizer que o saber metalingüístico canônico, instrumentalizado na nossa sociedade pelas gramáticas e pelos dicionários, transformado em mercadoria pela mídia, tal qual outros bens culturais, como a música, a literatura, as artes plásticas etc., constitui-se em mais uma das tecnologias de governamentabilidade dos corpos, ou seja, em mais um instrumento que visa a domesticar o sujeito, necessário para a existência e a manutenção da sociedade capitalista. Ademais, do mesmo modo que a mídia desenvolve campanhas de vacinação de idosos para diminuir os custos financeiros dos órgãos estatais e privados com internação, tratamento etc., cria 
também campanhas para "restabelecer" a saúde lingüística dos brasileiros, visto que os "problemas" de comunicação também geram prejuízos. Assim, pela lógica do utilitarismo extremo do capitalismo, quanto mais se gerenciam racionalmente as seqüências lingüísticas dos sujeitos, há menos possibilidades de falhas, prejuízos. Diante do exposto, acreditamos que, sob o pretexto de desenvolver o bem-estar lingüístico dos indivíduos e das populações, a mídia, com seu olhar panóptico, nos seus mais diversos suportes, desenvolve todo um processo de economização da língua. Irrompe o português-panóptico ${ }^{5}$. Mais um triunfo do "olhar-leitor-mercado" sobre a língua?

\section{Referências Bibliográficas}

ARANTES, Paulo Eduardo. O nome do sujeito. In: Folha de S. Paulo. Caderno Mais. 27/10 de 2002.

BAGNO, Marcos. Dramática da Língua Portuguesa: tradição gramatical, mídia e exclusão social. São Paulo: Edições Loyola, 2000.

BENTHAM, Jeremy. O panóptico. Belo Horizonte: Autêntica, 2000.

BOURDIEU, Pierre. A economia das trocas lingüísticas: o que falar quer dizer. $2^{\text {a }}$. ed. São Paulo: Editora da USP, 1998.

CUNHA, Celso. Língua Portuguesa e realidade brasileira. Rio de Janeiro: Tempo Brasileiro, 1975.

COURTINE, J-J. O chapéu de Clementis: observações sobre a memória e o esquecimento na enunciação do discurso político. In: INDURKY, F. e LEANDRO FERREIRA, M. C. (Orgs). Os múltiplos territórios da análise do discurso. Porto Alegre: RS, Editora Sagra Luzzato, 1999.

. A melhor das línguas. Trad. Bras. Simone Rosa Nunes Reis. UFRGS, 2002 (mímeo).

LE GOFF, Jacques \& SCHMITT, Jean-Claude (coord.).Dicionário Temático do Ocidente Medieval. Bauru, SP: EDUSC; São Paulo, SP: Imprensa Oficial do Estado, 2002.

ECO, Humberto. A busca da língua perfeita na cultura européia. Bauru, SP: EDUSC, 2001.

5 Como bom "ladrão de palavras", empresto a idéia dessa expressão da luminosa análise que Jean-Jacques Courtine realiza sobre o projeto de criação do basic-english de Orwell 1984. 
ELIAS, Norbert. O processo civilizador: uma história dos costumes, Rio de Janeiro, Jorge Zahar Ed. 1990, v. 1

. O processo civilizador: formação do estado e civilização Trad. da versão inglesa, Rui Jungmann, revisão, apresentação de notas, Renato Janine Ribeiro, Rio de Janeiro, Jorge Zahar Ed. 1993, v. 2

FOUCAULT, Michel. Vigiar e punir: nascimento da prisão. 13a . ed. Petrópolis, RJ: Vozes, 1977.

. Les mailles du pouvoir. In. Dits e écrits IV. Paris: Gallimard, 1981. A arqueologia do saber. $4^{\text {a }}$. ed. Rio de Janeiro: Forense Universitária, 1995.

. A verdade e as formas jurídicas. Rio de janeiro: Nau Editora, 1999.

A arqueologia das ciências e história dos sistemas de representação.

Rio de Janeiro: Forense Universitária, 2000.

. Estratégia, poder-saber. Rio de Janeiro: Forense Universitária, 2003.

GREGOLIN, Maria do Rosário Valencise. Foucault e os nossos trabalhos: um kit básico para os analistas de discurso que querem trazer Foucault para seus trabalhos. Grupo de Estudos em Análise do Discurso de Araraquara - GEADA, 2002 (mímeo).

HARDT, M. \& NEGRI, A Império. Rio de Janeiro: Record, 2001.

MACHADO, R. Introdução: Por uma genealogia do poder. In; FOUCAULT, M. Microfísica do poder. 13a . ed. Rio de Janeiro, edições, Graal, 1998.

MILNER, Jean-Claude. O amor da língua. Porto Alegre: Artes Médicas, 1987.

PÊCHEUX, Michel. Delimitações inversões, deslocamentos. In: Cadernos de Estudos lingüísticos, 19. Campinas, IEL, Unicamp, 1990.

. Lire L'Arquive Aujourd'Hui. In: Archives et documents, 2, St Cloud. Trad. Bras. In. ORLANDI, E. Gestos de Leitura. Campinas: Ed. da Unicamp, 1996.

POSSENTI, Sírio. Discurso, estilo e subjetividade. São Paulo: Martins Fontes, 1993.

. A cor da língua: e outras croniquinhas de lingüistica. Campinas, SP: Mercado de Letras/Associação de Leitura do Brasil, 2001. 